\title{
Effects of ferrous carbamoyl glycine on iron state and absorption in an iron-deficient rat model
}

\author{
Yuzhe Zhang ${ }^{1} \cdot$ Xiaoming Sun $^{1} \cdot$ Chunyan $\mathrm{Xie}^{1} \cdot$ Xugang Shu $^{1,2,3}$. \\ Abimbola Oladele Oso ${ }^{1,4} \cdot$ Zheng Ruan $^{2} \cdot$ Ze-yuan Deng ${ }^{2} \cdot$ Xin Wu ${ }^{1,2}$. \\ Yulong Yin ${ }^{1,2}$
}

Received: 1 June 2015/Accepted: 2 November 2015/Published online: 19 November 2015

(c) Springer-Verlag Berlin Heidelberg 2015

\begin{abstract}
An iron-deficient rat model was established and used to determine the effects of different iron sources on iron metabolism and absorption. Iron-deficient rats were assigned to one of three treatment groups, and their diet was supplemented with deionized water (control), FeCGly, or $\mathrm{FeSO}_{4}$ for 8 days via intragastric administration. Blood samples were obtained for analysis of iron-related properties, and the small intestine and liver were removed for quantitative reverse transcription PCR of genes related to iron metabolism. The serum total iron-binding capacity (TIBC) levels of rats in Fe-CGly and $\mathrm{FeSO}_{4}$ supplementation groups was lower $(P<0.05)$ than that of the rats in the control group. The rats in Fe-CGly group exhibited higher $(P<0.05)$ plasma $\mathrm{Fe}$ and ferritin levels and lower $(P<0.05)$ TIBC levels compared with the rats in $\mathrm{FeSO}_{4}$
\end{abstract}

Xiaoming Sun and Chunyan Xie have contributed to the Yuzhe Zhang.

$\mathrm{Xin} \mathrm{Wu}$

w.xin@foxmail.com; wuxin@isa.ac.cn

Yulong Yin

yinyulong@isa.ac.cn

1 Hunan Provincial Engineering Research Center of Healthy Livestock, Key Laboratory of Agro-ecological Processes in Subtropical Region, Institute of Subtropical Agriculture, Chinese Academy of Sciences, Changsha, Hunan 410125, China

2 State Key Laboratory of Food Science and Technology and College of Life Science and Food Engineering, Nanchang University, Nanchang 330031, China

3 Guangzhou Tanke BIO-TECH Co. Ltd., Guangzhou 510800, China

4 Department of Animal Nutrition, College of Animal Science and Livestock Production, PMB 2240 Abeokuta, Nigeria groups. The relative expression of liver hepcidin increased $(P<0.05)$ by tenfold and 80 -fold in the Fe-CGly and $\mathrm{FeSO}_{4}$ groups, respectively, whereas divalent metal transporter 1 , duodenal cytochrome $b$, and ferroportin 1 expression decreased $(P<0.05)$ in the duodenum in both $\mathrm{Fe}-\mathrm{CGly}$ and $\mathrm{FeSO}_{4}$ group. A comparison between FeCGly and $\mathrm{FeSO}_{4}$ group showed that iron regulatory protein 1 (IRP1) and iron regulatory protein (IRP2) expressions were reduced $(P<0.05)$ in rats administered $\mathrm{FeSO}_{4}$ than in rats administered with $\mathrm{Fe}-\mathrm{Cgly}$. These results indicate that Fe-CGly rapidly improves the blood iron status and that IRP1 and IRP2 may play an important role in the intestinal absorption of Fe-CGly.

Keywords Ferrous carbamoyl glycine - Hepcidin . IRP1/IRP2 $\cdot$ SD rats $\cdot$ FeSO4

\section{Introduction}

Iron $(\mathrm{Fe})$ is a vital mineral that is essential for aerobic metabolism in many organisms; it contributes to various physiological functions such as oxygen transport and energy metabolism (Oliveira et al. 2014). The major biological function of iron requires its incorporation into proteins and enzymes such as hemoglobin and myoglobin. The relationship between dietary supplementation of iron and various pathological states in the body like iron deficiency and iron deficiency anemia (IDA) has been extensively investigated (Peto 2010). Iron deficiency and iron deficiency anemia (IDA) are micronutrient malnutrition conditions widespread in humans, livestock, and micro-livestock (such as rabbit and poultry) (Stoltzfus 2001). In contrast, excessive iron may lead to microbial infections or cause tissue damage. The biological 
concentration of iron must therefore be closely monitored and regulated (Oliveira et al. 2014). Iron homeostasis in body tissues is balanced by two regulatory systems: One system functions systemically and relies on the hormone hepcidin and the iron exporter ferroportin, and the second system predominantly controls cellular iron metabolism through iron regulatory proteins that bind iron-responsive elements in regulated messenger RNAs (mRNAs) (Hentze et al. 2010).

Iron additives are important for the diet of both humans and livestock. To date, three stages of development of iron additives, corresponding to three generations of products, have been noted. The first generation consisted of inorganic iron sources such as ferrous chloride, ferrous sulfate, and ferrous carbonate. These inorganic sources have very poor biological availability and complex with other nutrients in the gut. The second generation consisted of simple organic iron sources such as ferrous fumarate and ferrous citrate; however, the biological activity of these compounds is low, and they may have adverse effects on other feed components (Wang et al. 2010). Therefore, researchers working with microlivestock sought to develop safe and efficient forage additives that would overcome the shortcomings of the aforementioned iron additives.

One of such compound is iron carbamoyl glycine chelate (Fe-CGly), which has greater absorbability than other Fe sources (Wu et al. 2013; Wan et al. 2015). With the attendant benefits of increased absorption rate, better growth of animals, improved immunity, and increased compatibility with the environment, iron-amino acid chelates have recently received increased attention in animal nutrition (Hertrampf and Olivares 2004). Chelates of mineral are more bioavailable and efficiently absorbed from gut than those provided by inorganic salts (Vegarud et al. 2000). In addition, mineral chelates can potentially reduce mineral excretion and environmental contamination (Singh et al. 2015).

The improved bioavailability of iron-amino acid chelates has been attributed to highly efficient absorption, but the mechanism underlying the efficient absorption is unclear. This study therefore seeks to investigate the effects of Fe-CGly on the iron state and absorption in an irondeficient rat model.

\section{Materials and methods}

\section{Animals and treatments}

Thirty male Sprague-Dawley (SD) rats were used to determine the effects of Fe-CGly on iron absorption and regulation. These SD rats were fed for 14 days pre- experimental period with an iron-deficient diet in order to stimulate a 'nutritional anemia status' (Blood hemoglobin level $(<120 \mathrm{~g} / \mathrm{L})$ indicated the nutritional anemia status) (Borel et al. 1991). The Hb levels of normal or anemic rats are presented in Table 1. The iron-deficient rat model was built after the pre-experimental period, and then the anemic rats $(\mathrm{Hb}$ level were about $95 \mathrm{~g} / \mathrm{L}$ ) were subsequently used to determine the effects of Fe-CGly on iron absorption and regulation. In total, 30 rats with an average weight of $116 \pm 2.35 \mathrm{~g}$ were allotted on a weight equalization basis to one of the three treatment groups (10 rats per treatment): control, Fe-CGly, and $\mathrm{FeSO}_{4}$ groups. The experimental treatment consisted of daily administration of $1 \mathrm{~mL}$ of deionized water (control), $1.88 \mathrm{mmol} \mathrm{Fe}-\mathrm{CGly}$, or $1.88 \mathrm{mmol} \mathrm{FeSO}_{4}$, respectively, for a period of 8 days by gavage. The offered Fe quantity in $\mathrm{Fe}-\mathrm{Cgly}$ or $\mathrm{FeSO}_{4}$ group was enough for the recovery of $\mathrm{Hb}$ level (Weber et al. 2010).

All rats were fed with basal diet having a previously established composition (Wu et al. 2012; Zhou et al. 2012). The basal diet contained $397.5 \mathrm{~g} / \mathrm{kg}$ corn, $200 \mathrm{~g} / \mathrm{kg}$ casein, $132 \mathrm{~g} / \mathrm{kg}$ maltodextrin, $100 \mathrm{~g} / \mathrm{kg}$ sucrose, $70 \mathrm{~g} / \mathrm{kg}$ corn oil, $50 \mathrm{~g} / \mathrm{kg}$ fibers (cellulose), $30 \mathrm{~g} / \mathrm{kg}$ canola, $35 \mathrm{~g} / \mathrm{kg}$ mineral mixture (with no iron), $10 \mathrm{~g} / \mathrm{kg}$ vitamin mixture, $3 \mathrm{~g} / \mathrm{kg}$ DL-methionine, $100 \mathrm{~g} / \mathrm{kg}$ sodium chloride, and $2 \mathrm{~g} / \mathrm{kg}$ choline bitartrate. The detected trace element content was $987.9 \mathrm{mg} / \mathrm{kg}$ for Al, $36.2 \mathrm{mg} / \mathrm{kg}$ for $\mathrm{Zn}$, and $24.1 \mathrm{mg} / \mathrm{kg}$ for Fe.

The animals were housed individually in cages $(26.0 \mathrm{~cm} \times 19.0 \mathrm{~cm})$ and fed a ration prepared according to the recommendations of the American Institute of Nutrition (1993) for adult rats (Lien et al. 2001). The rats were maintained under a controlled environment at $22{ }^{\circ} \mathrm{C} \pm 2{ }^{\circ} \mathrm{C}$ and relative air humidity of $60 \% \pm 10 \%$ under a 12-h daylight/dark cycle (dark from 0800 to $2000 \mathrm{~h}$ ), with water and food available ad libitum throughout the experiment (Wu et al. 2012; Zhou et al. 2012).

Fe-CGly $\left(\mathrm{C}_{6} \mathrm{H}_{10} \mathrm{~N}_{4} \mathrm{O}_{6} \mathrm{Fe}\right)$ was obtained from Guangzhou Tanke Bio-Tech Co. Ltd (Guangzhou, China; $>99.99 \%$ purity, $24 \%$ iron content). All of the other reagents used in this study were of analytical grade or better quality. This study was performed in accordance with the Chinese guidelines for animal welfare and approved by the Animal Care and Use Committee of the Institute of Subtropical Agriculture of the Chinese Academy of Sciences.

Table $1 \mathrm{Hb}$ levels of normal or anemic rats in the present study

\begin{tabular}{lcc}
\hline & Normal SD rat & Anemic SD rat \\
\hline $\mathrm{Hb}(\mathrm{g} / \mathrm{L})$ & $148.45 \pm 12.32$ & $95.19 \pm 5.85$ \\
\hline
\end{tabular}




\section{Sample collection}

At $0800 \mathrm{~h}$ on day 8 , all animals were deprived of basal diet and killed by exsanguination (anaesthetized before exsanguination). Blood samples (1.5 $\mathrm{mL}$ per rat) were collected and centrifuged to obtain plasma, which was stored at $-20{ }^{\circ} \mathrm{C}$ until analysis. The small intestine and liver were excised, and the duodenum, jejunum, and ileum were separated, thoroughly flushed with sterile saline, immediately frozen in liquid nitrogen, and then stored at $-80{ }^{\circ} \mathrm{C}$ for mRNA analysis (Wu et al. 2015).

\section{Fe analysis}

The samples (liver, kidney, and spleen) were digested by the microwave digestion system MK-II (Shanghai Shin Co., Shanghai, China) using a Milli Q microwave digester (Millipore Corp., Bedford, MA, USA). Fe levels were determined by inductively coupled plasma mass spectrometry (ICP-MS) (ELAN6000, PerkinElmer SCIEX, USA) with the same operating parameters as previously described (Wu et al. 2012). All vessels used in this experiment were treated with $10 \%$ nitric acid for over $24 \mathrm{~h}$.

\section{Determination of blood iron properties}

Blood hemoglobin $(\mathrm{Hb})$, red blood cell (RBC) number, and mean corpuscular volume (MCV) were estimated using an automatic hematology analyzer (Cell-Dyn 4000, Abbott Laboratories, Abbott Park, IL, USA). An automated biochemistry analyzer (Synchron CX Pro; Beckman Coulter, Fullerton, CA, USA) was used to determine the total ironbinding capacity (TIBC) of the samples. Commercial kits for these indexes were purchased from Beijing Chemclin Biotech Co., Ltd. (Beijing, China) and used according to the manufacturer's instructions. The ELISA commercial kit used for plasma ferritin determination was also purchased from Beijing Chemclin Biotech Co., Ltd. (Beijing, China).

\section{Quantitative reverse transcription PCR (qRT-PCR)}

Total RNA was isolated from small intestine and liver samples using TRIzol reagent (Life Technologies, Carlsbad, CA, USA) according to the manufacturer's instructions. Total RNA was reverse-transcribed into cDNA using the SuperScript First-Strand Synthesis System kit (Life Technologies),

Quantitative PCR analyses were performed on an ABI 7900HT system. Quantitative PCR amplification (Applied Biosystems, Foster City, CA, USA) was performed in a total volume of $10 \mu \mathrm{L}$, including cDNA, SYBR Green mix, ROX reference dye, and specific primers. The PCR primer pairs that were used to amplify hepcidin, divalent metal transporter $(D M T 1)$, ferroportin 1 (Fpnl), duodenal cytochrome $\mathrm{b}(D c y t b)$, iron regulatory protein 1 (IRPI), iron regulatory protein 2 (IRP2), and $\beta$-actin cDNA fragments are listed in Table 2. The qRT-PCR conditions were as follows: $30 \mathrm{~s}$ of denaturation at $94{ }^{\circ} \mathrm{C}$ followed by 30 cycles of $30 \mathrm{~s}$ of annealing at $60{ }^{\circ} \mathrm{C}$, and $30 \mathrm{~s}$ of extension at $72{ }^{\circ} \mathrm{C}$. Relative quantification of gene amplification by qRT-PCR was performed using cycle threshold $(\mathrm{Ct})$ values. The comparative $\mathrm{Ct}$ value method was employed to quantitate expression levels for genes relative to those for $\beta$-actin.

\section{Western blot}

Frozen samples were powdered under liquid nitrogen, and lysed in RIPA buffer $(150 \mathrm{mM} \mathrm{NaCl}, 1 \%$ Triton X-100, $0.5 \%$ sodium deoxycholate, $0.1 \%$ SDS, $50 \mathrm{mM}$ Tris- $\mathrm{HCl}$ at $\mathrm{pH}$ 7.4), plus a protease inhibitor cocktail (Roche, Shanghai, China) and phosphatase inhibitors (Thermo Scientific, Bremen, Germany). Soluble proteins were subjected to SDS-PAGE, and transferred to PVDF membranes (Millipore, Billerica, MA), blocked with $5 \%$ nonfat milk in TBS- $0.05 \%$ Tween- 20 for $1 \mathrm{~h}$ and incubated overnight with iron regulatory protein 1 (IPR $1 ; 1: 500)$, iron regulatory protein 2 (IPR $2 ; 1: 500)$, and $\beta$-actin $(1: 1000)$ (Santa Cruz, CA, USA) antibodies followed by horseradish peroxidase-linked secondary antibodies (Santa Cruz, CA, USA). The immunostaining signals were detected with enhanced chemiluminescence kit (Applygen Technologies Inc., Beijing, China). The density of the specific protein bands of interest was measured using AlphaImager 2200 (Alpha Innotech Corporation, CA, USA) software and normalized by that of $\beta$-actin.

\section{Statistical analysis}

Data were subjected to analysis of variance (ANOVA) in a completely randomized design (CRD) and were analyzed using SPSS 13.0 (SPSS, USA). Data are presented as the mean \pm SEM. Differences between significant means were separated using Tukey's test. Significant differences were considered at $P<0.05$.

\section{Results}

\section{Growth and iron-associated phenotype of treated and control rats}

Administration with Fe-CGly and $\mathrm{FeSO}_{4}$ showed no significant effect $(P>0.05)$ on final body weight and weight gain of rats (Table 3 ). We then examined the blood iron- 
Table 2 Sequences of primers for hepcidin, DMT1, Fpn1, Dcytb, IRP1, IRP2, and $\beta$-actin

Table 3 Effects of intragastric administration of ferrous carbamoyl glycine chelate on the growth of anemic SD rats

\begin{tabular}{llll}
\hline Genes & Primer & $5^{\prime}-3^{\prime}$ & Products (bp) \\
\hline Hepcidin & Forward & GCTGCCTGTCTCCTGCTTCT & 160 \\
& Reverse & TGGTGTCTCGCTTCCTTCG & 102 \\
DMT1 & Forward & CTACTTGGGTTGGCAGTGTTTG & \\
& Reverse & CCGCTGGTATCTTCGCTCA & 145 \\
Fpn1 & Forward & TCGTAGCAGGAGAAAACAGG & 107 \\
& Reverse & GAAATGAAACCACAGCCAAT & \\
Dcytb & Forward & TCTGGACTCCTCCTCTTTGG & 155 \\
& Reverse & TCTGGTGGGAATGAATGGT & \\
IRP1 & Forward & TGGGGTGTAGGTGGTATTGA & 193 \\
IRP2 & Reverse & TGTCGGAGGTGCTTGGTA & \\
& Forward & AAGCCGAAACTCAGGAACA & 134 \\
& Reverse & AGGAGGGATGACTGCCACA & \\
\hline
\end{tabular}

\begin{tabular}{llll}
\hline & Initial body weight $(\mathrm{g})$ & Final body weight $(\mathrm{g})$ & Gain $(\mathrm{g})$ \\
\hline Control group & $116.1 \pm 7.4$ & $126.1 \pm 8.6$ & $10.0 \pm 2.4$ \\
Fe-CGly & $115.8 \pm 7.0$ & $126.2 \pm 8.3$ & $10.4 \pm 1.8$ \\
FeSO4 & $117.7 \pm 6.9$ & $127.9 \pm 7.9$ & $10.2 \pm 2.5$ \\
\hline
\end{tabular}

Data are expressed as mean $\pm \mathrm{SEM}, n=8$. Values in a row with different superscript differ $(P<0.05)$
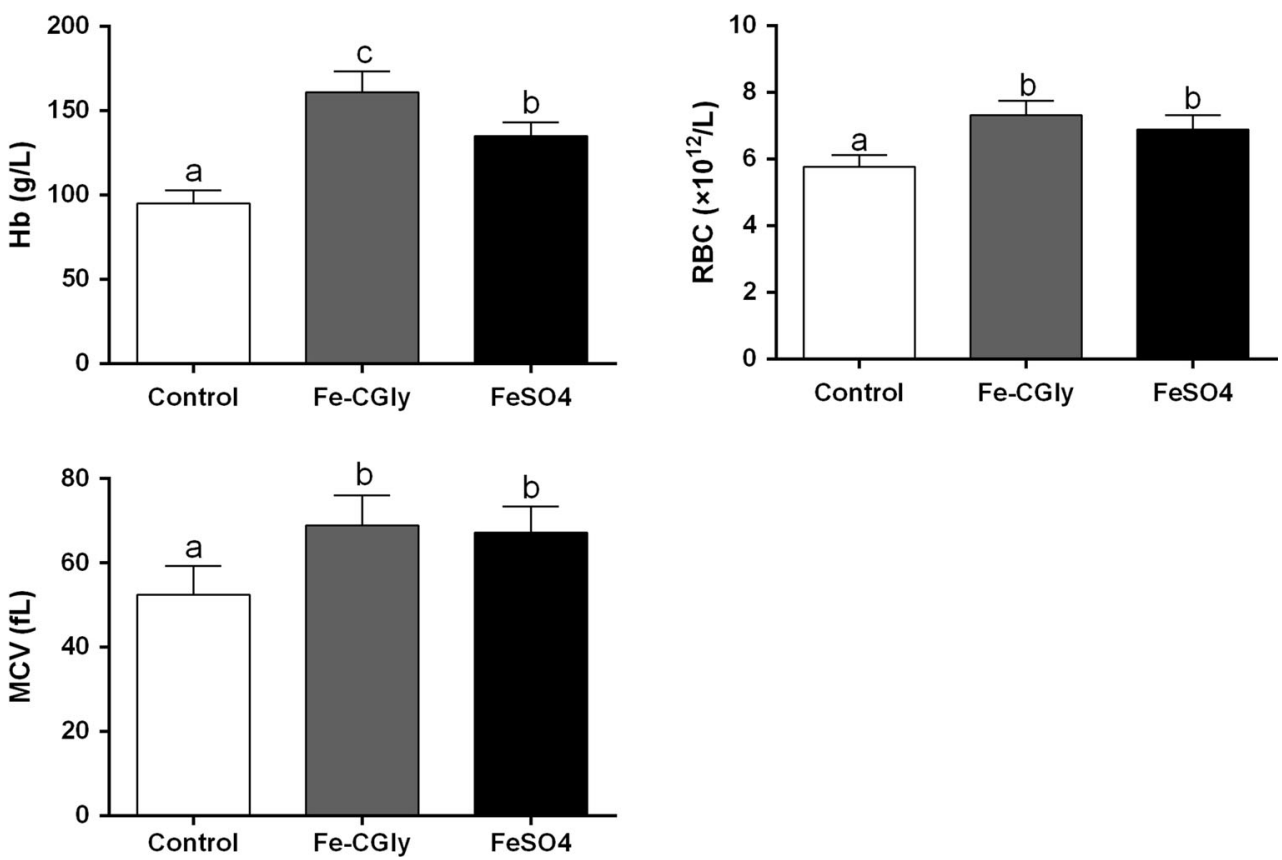

Fig. 1 Effects of intragastric administration of ferrous carbamoyl glycine chelate on iron-associated properties of the blood of anemic SD rats. Data are expressed as mean \pm SEM, $n=8$. Values with different superscript differ $(P<0.05)$ associated properties (Fig. 1). Furthermore, administration of Fe-CGly increased $(P<0.05) \mathrm{Hb}$ levels $(3.97 \%)$ to a greater extent than $\mathrm{FeSO}_{4}$ did. Control group had the lowest $(P>0.05) \mathrm{Hb}$ levels. Administration of Fe-CGly or $\mathrm{FeSO}_{4}$ resulted in increased RBC and MCV levels when compared with the control group. However, similar values of $\mathrm{RBC}$ and MCV were obtained for rats fed with diets supplemented with Fe-CGly and $\mathrm{FeSO}_{4}$. When compared with the control group, rats administered Fe-CGly exhibited higher $(P<0.05)$ serum $\mathrm{Fe}(7.66 \%)$ and ferritin 
levels $(4.79 \%)$ and lower $(P<0.05)$ TIBC levels $(12.54 \%)$. A comparison between the two iron sources showed higher $(P<0.05)$ serum iron $(3.73$, ferritin $(3.07 \%)$ levels, and lower TIBC levels $(2.49 \%)$ in rats administered Fe-CGly than in those administered $\mathrm{FeSO}_{4}$ (Fig. 2). Thus, Fe-CGLy increased serum iron and ferritin concentration in anemic rats and decreased TIBC in more effective way than $\mathrm{FeSO} 4$ in anemic rats.

\section{Effect of iron supplementation on iron levels in tissues (liver, kidney, and spleen)}

As shown in Fig. 3, following administration with FeCGly, iron levels in the liver $(15 \%)$ and spleen $(20.12 \%)$ increased significantly $(P<0.05)$. A comparison between Fe-CGly and $\mathrm{FeSO}_{4}$ group showed similar iron concentration in liver and spleen samples. After iron administration, the iron content of the kidneys did not change significantly in either Fe-CGly or $\mathrm{FeSO}_{4}$ groups $(P>0.05)$.

\section{Expression of genes associated with iron homeostasis}

Highest $(P<0.05)$ gene expression of hepcidin in the liver was obtained with $\mathrm{FeSO}_{4}$ group, followed by Fe-CGly, while the lowest $(P<0.05)$ expression was noticed with control group (Fig. 4). Subsequently, the expression of genes involved in iron uptake in the duodenum was also determined (Fig. 5). DMT1, Fpnl, and Dcytb mRNA expression decreased $(P<0.05)$ in rats receiving either FeCGly or $\mathrm{FeSO}_{4}$ relative to that in the control group
$(P<0.05)$ with no significant differences between $\mathrm{Fe}$ CGly and FeSO4 group. Finally, the gene expressions of IRPI and IRP 2, which encode global iron regulators, were determined in the duodenum (Fig. 6a). A comparison between Fe-CGly and $\mathrm{FeSO}_{4}$ group showed that IRPI and $I R P 2$ expressions were reduced in rats administered $\mathrm{FeSO}_{4}$ than in rats administered with Fe-CGly. In rats that received Fe-CGly, IRPI expression increased significantly compared with that in the $\mathrm{FeSO}_{4}$ and control group $(P<0.05)$. The protein expression of IRPI and IRP2 were also determined in the duodenum (Fig. 6b). In rats that received Fe-CGly, the protein expression of IRPI and IRP2 increased significantly compared with that in the $\mathrm{FeSO}_{4}$ and control group $(P<0.05)$.

\section{Discussion}

Iron plays an important role in many metabolic processes of the body. The present study confirmed that administration with either Fe-CGly or $\mathrm{FeSO}_{4}$ showed no effect on the growth performance of rats. The fact that the blood $\mathrm{Hb}$ concentration of rats were restored when administered either of the 2 iron sources (Fe-CGly or $\mathrm{FeSO}_{4}$ ) in this study confirmed that iron administration generally promoted improved blood $\mathrm{Hb}$ concentration. However, the increased plasma Fe level, ferritin, and faster increase in blood $\mathrm{Hb}$ levels recorded in rats administered Fe-CGly than their counterparts administered $\mathrm{FeSO}_{4}$ implied a higher bioavailability of iron in rats administered iron ferritin than $\mathrm{FeSO}_{4}$ group. Improved bioavailability of iron
Fig. 2 Effects of intragastric administration of ferrous carbamoyl glycine chelate on plasma iron, TIBC, and ferritin concentrations in anemic SD rats. Data are expressed as mean \pm SEM, $n=8$. Values with different superscript differ $(P<0.05)$
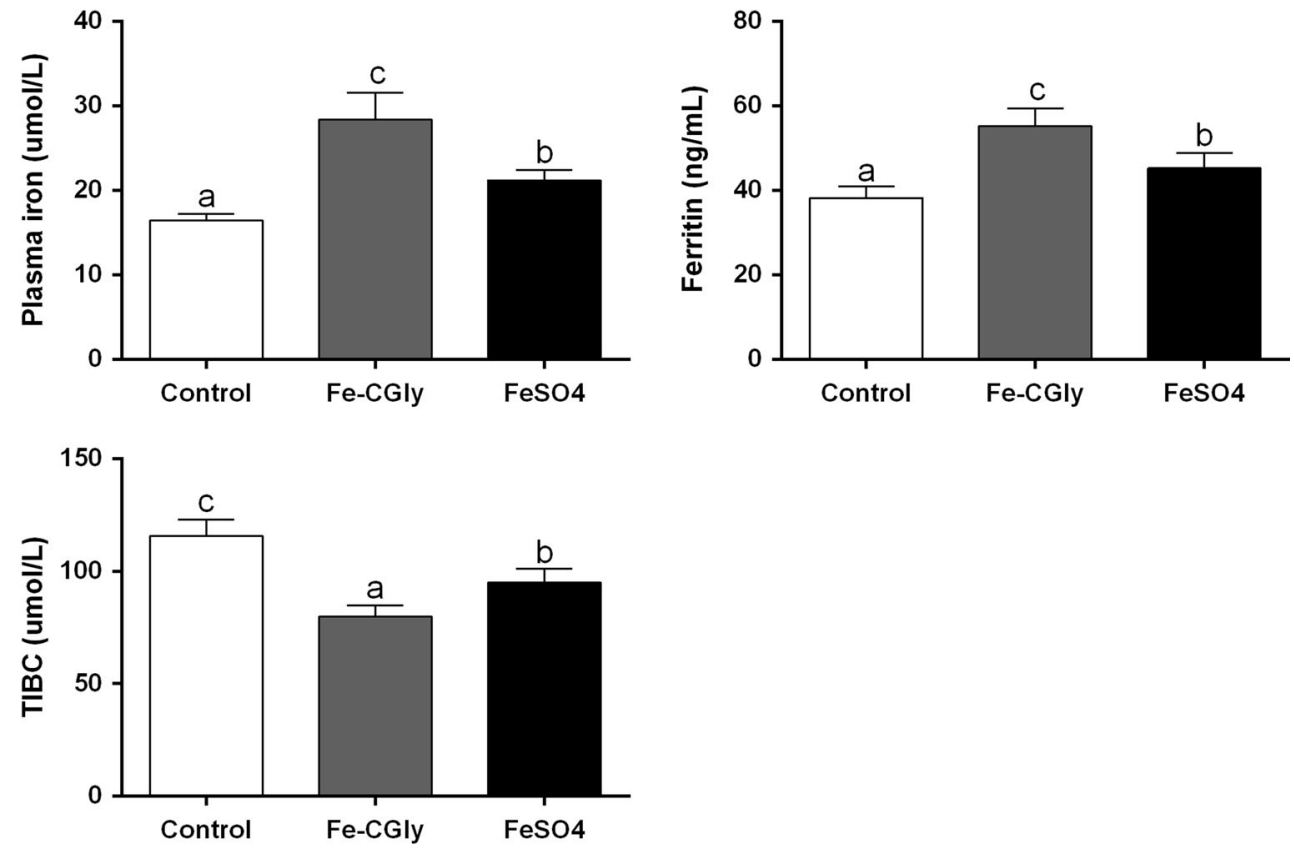
Fig. 3 Effects of intragastric administration of ferrous carbamoyl glycine chelate on tissue $\mathrm{Fe}$ in the livers, kidneys, and spleens of anemic rats. Data are expressed as mean $\pm \mathrm{SEM}$, $n=8$. Values with different superscript differ $(P<0.05)$
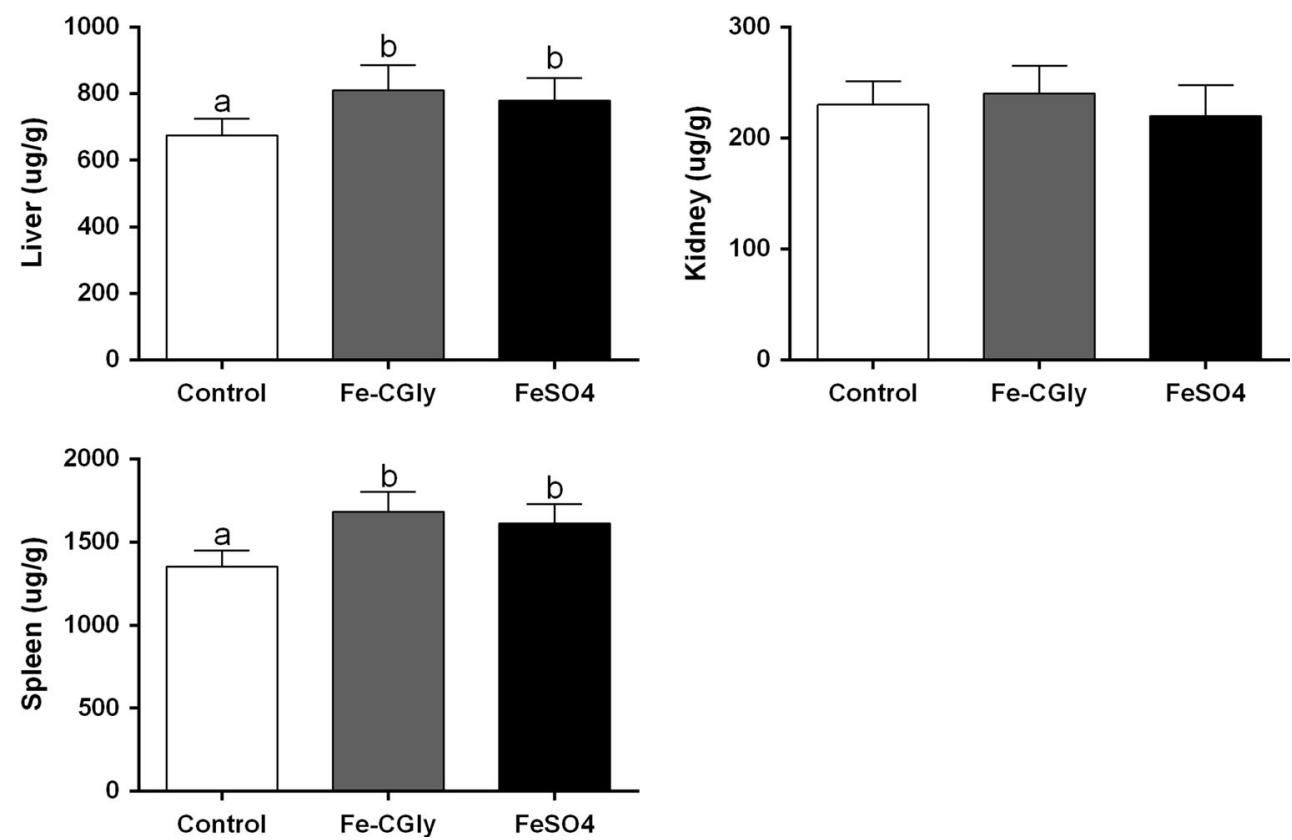

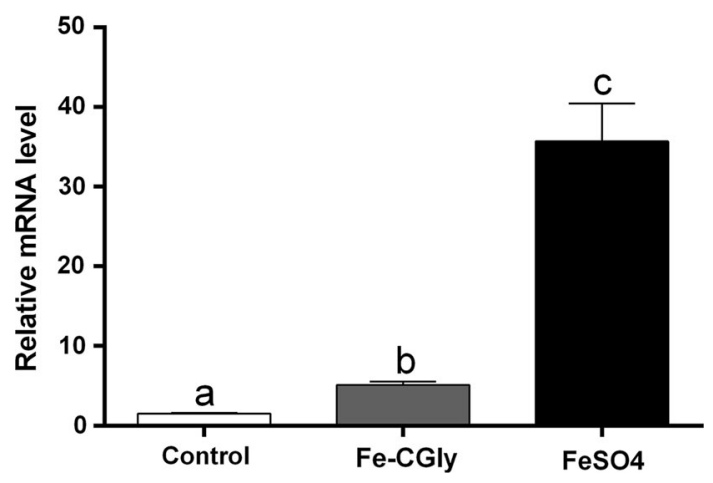

Fig. 4 Hepcidin mRNA expression levels following the administration of FeCGly or FeSO4. Data are expressed as mean $\pm \mathrm{SEM}$, $n=8$. Values with different superscript differ $(P<0.05)$

in Fe-CGly group could be attributed to the excellent chemical stability, high biological value, and high solubility of iron in the amino acid chelates (Ashmead 2001; Hertrampf and Olivares 2004). The trend observed in this study agreed with previous findings which showed improved iron absorption in glycine-chelated iron than ferrous sulfate (Bovell-Benjamin et al. 2000).

Liver is a reliable response criterion of mineral status and relative bioavailability (Bailey et al. 2001). Increased liver iron concentration recorded with rats on Fe-CGly and $\mathrm{FeSO}_{4}$ when compared to control group confirmed the assertion that iron administration directly influences their concentration in organs. The low liver and spleen iron concentration recorded for rats on control group could be attributed to deficient iron levels of the diet. As expected, Fe-CGly should improve the visceral iron concentration. However, administration of either Fe-CGly or $\mathrm{FeSO}_{4}$ in the current study showed similar iron concentration in liver and spleen samples. This may be due to the greater catabolism of iron in liver and spleen of pigs in Fe-CGly group.

In the present study, highest hepcidin expression was obtained with $\mathrm{FeSO}_{4}$ group than $\mathrm{Fe}-\mathrm{CGly}$ group. Hepcidin regulates the activity of ferroportin1 (Fpn1), an intestinal
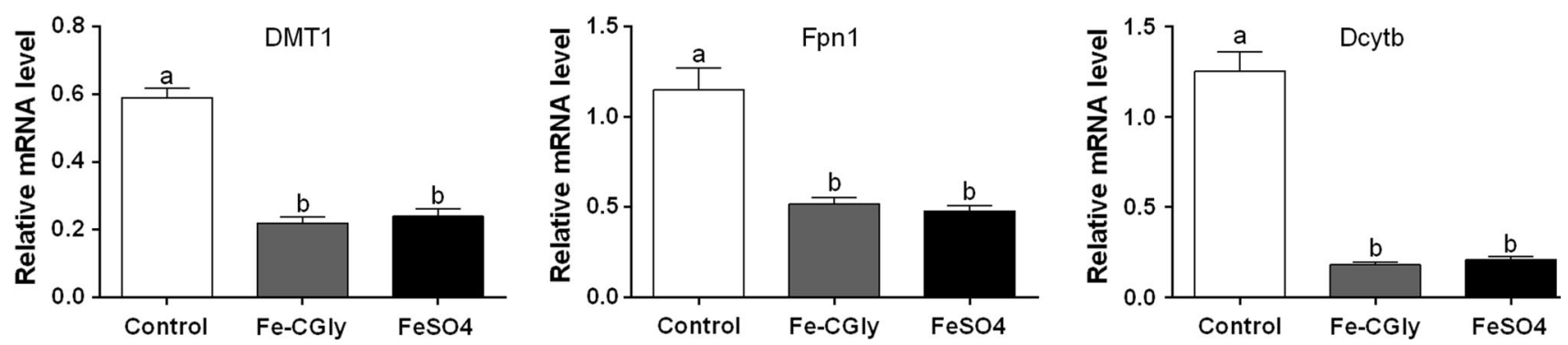

Fig. 5 DMT1, Fpn 1, and Dcytb mRNA expression levels in the duodenum following the administration of FeCGly or FeSO4. Data are expressed as mean \pm SEM, $n=8$. Values with different superscript differ $(P<0.05)$ 
Fig. $6 I R P 1$ and $I R P 2$ expression levels (a mRNA level, b protein level) in the duodenum following the administration of FeCGly or FeSO4. ${ }^{1}$ control group, ${ }^{2} \mathrm{Fe}$ Cgly group, ${ }^{3} \mathrm{FeSO} 4$ group. Data are expressed as mean \pm SEM, $n=8$. Values with different superscript differ $(P<0.05)$
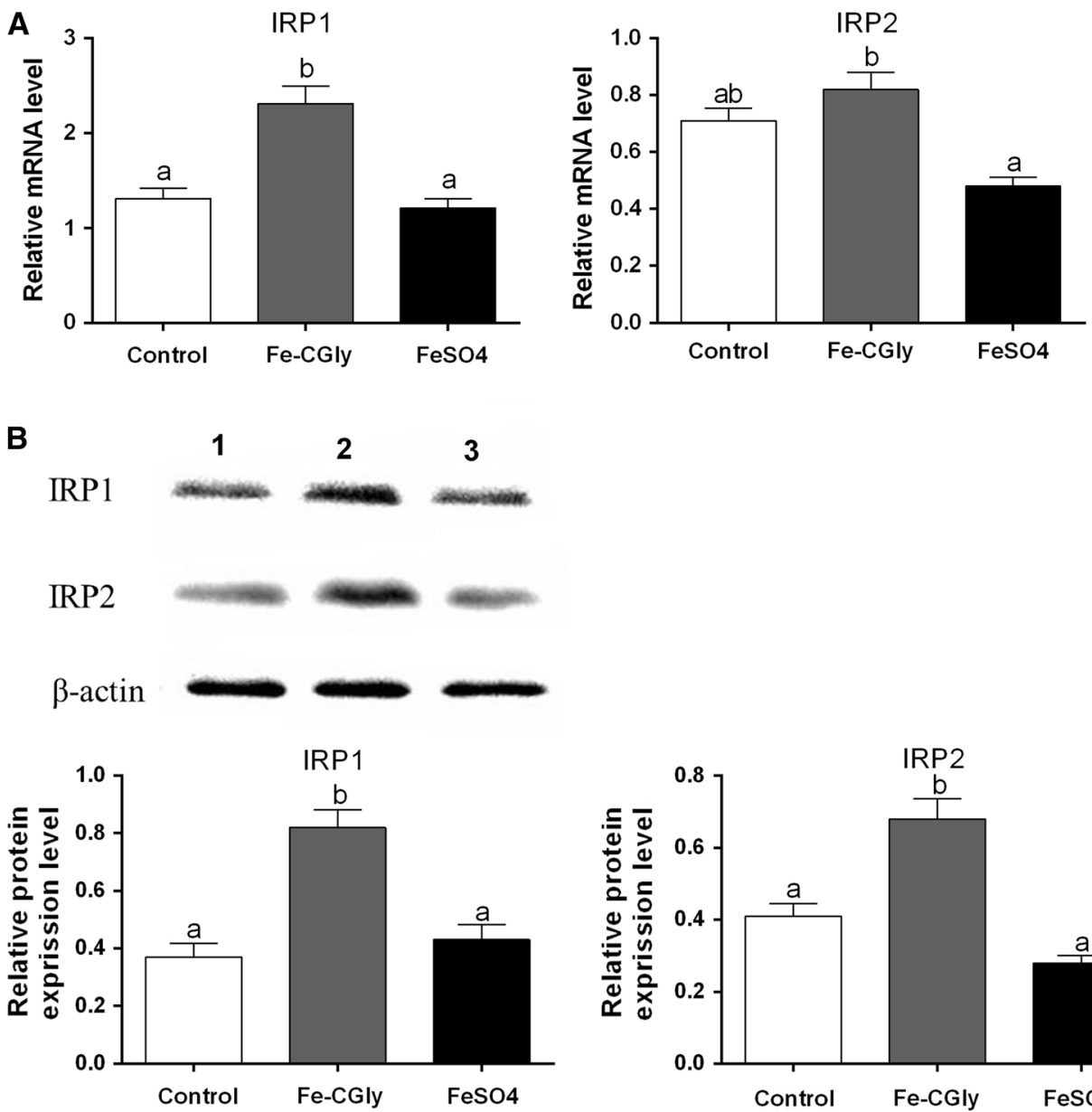

and macrophage iron exporter, by inducing its internalization and degradation (Ross et al. 2012). Hepcidin is a peptide hormone secreted by the liver in response to iron loading and inflammation (Nemeth et al. 2004), and its expression is regulated in response to the iron content in the body (De Domenico et al. 2007). Body iron homeostasis is maintained by the hepcidin-Fpn1 regulatory axis and the cellular IRE/IRP (iron regulatory element, iron regulatory protein) system for regulating the expression of iron absorption- and transport-related proteins (Lash and Saleem 1995; Hentze et al. 2010; Theil 2011). The blood iron concentration is a direct reflection of the iron content in the body. So, compared with $\mathrm{FeSO}_{4}$ group, the suppression of hepcidin expression in Fe-Cgly group may be due to the higher blood iron concentration.

When the body is in a state of iron deficiency, the rate of intestinal absorption of iron is accelerated. DMT1 is the only known membrane transporter for the intestinal absorption of non-heme iron, primarily at the duodenum brush border (Andrews 1999). The dietary levels of iron influence DMT1 expression and distribution. During iron deficiency, DMT1 mRNA levels increase at the rat duodenal crypt-villus junction, and DMT1 protein is mainly distributed in the cell membranes on the free surface of intestinal microvilli. Under normal iron levels, DMT1 is mainly distributed in the cytoplasm (Frazer et al. 2007). In a subtype of DMT1 with the mRNA $3^{\prime}$-UTR containing an iron response element (IRE), DMT1 expression is regulated by iron levels via the IRE/IRP system (Schneider and Leibold 2003). In IRP system mainly including IRP1 and IRP2, IRP1 emerged as a key regulator of erythropoiesis and iron absorption by controlling hypoxia inducible factor $2 \alpha$ (HIF $2 \alpha)$ mRNA translation, while IRP2 appears to dominate the control of iron uptake and heme biosynthesis in erythroid progenitor cells by regulating the expression of transferrin receptor 1 (TfR1) and 5-aminolevulinic acid synthase 2 (ALAS2) mRNAs, respectively (Wilkinson and Pantopoulos 2014).

The results of the present study revealed that hepcidin expression levels in the rat liver were elevated after iron supplementation, indicating that hepcidin secretion into the bloodstream was also elevated, thereby decreasing Fpn1 expression in the duodenal mucosa. The iron content in the liver and spleen of rats fed an iron-supplemented diet showed marked improvement with both supplements. Compared to the control group, SD anemic rats that 
received both $\mathrm{Fe}-\mathrm{Cgly}$ and $\mathrm{FeSO}_{4}$ showed decreased duodenal expression of DMTI, Dcytb, and Fpnl, indicating that the capacity for intestinal absorption of $\mathrm{Fe}^{2+}$ decreased significantly. Additionally, the gene and protein levels of IRP1/IRP2 were higher in the Fe-CGly group than in the control and $\mathrm{FeSO}_{4}$ groups. Thus, we thought that IRP1/2 may play an important role in the intestinal absorption of Fe-Cgly.

\section{Conclusion}

Our results indicated that compared to the inorganic $\mathrm{FeSO}_{4}, \mathrm{Fe}-\mathrm{CGly}$ can rapidly improve the blood iron status of anemic rats in vivo. Furthermore, $\mathrm{Fe}-\mathrm{CGly}$ and $\mathrm{FeSO}_{4}$ may have similar roles in the body, and IRP1/IRP2 may play an important role in the absorption process of $\mathrm{Fe}$ CGly.

Acknowledgments This paper was jointly supported by Grants from the NSFC (31110103909), the National Key Technology Research and Development Program of the Ministry of Science and Technology of China (2012BAD39B00), Chinese Academy of Sciences comprehensive strategic cooperation project of Guangdong Province (2013B091500095, 2013B090900007), and major Project of Hunan Province (2015NK1002).

\section{Compliance with ethical standards}

Conflict of interest None of the authors has any conflict of interest to declare.

\section{References}

Andrews NC (1999) The iron transporter DMT1. Int J Biochem Cell Biol 31:991-994

Ashmead HD (2001) The absorption and metabolism of iron amino acid chelate. Arch Latinoam Nutr 51:13-21

Bailey JD, Ansotegui RP, Paterson JA, Swenson CK, Johnson AB (2001) Effects of supplementing combinations of inorganic and complexed copper on performance and liver mineral status of beef heifers consuming antagonists. J Anim Sci 79:2926-2934

Borel MJ, Smfth SH, Brigham DE, Beard JL (1991) The impact of varying degrees of iron nutriture on several functional consequences of iron deficiency in rats. J Nutr 121:729-736

Bovell-Benjamin AC, Viteri FE, Allen LH (2000) Iron absorption from ferrous bisglycinate and ferric trisglycinate in whole maize is regulated by iron status. Am J Clin Nutr 71:1563-1569

De Domenico I, Ward DM, Langelier C, Vaughn MB, Nemeth E, Sundquist WI, Ganz T, Musci G, Kaplan J (2007) The molecular mechanism of hepcidin-mediated ferroportin down-regulation. Mol Biol Cell 18:2569-2578

Frazer DM, Wilkins SJ, Anderson GJ (2007) Elevated iron absorption in the neonatal rat reflects high expression of iron transport genes in the distal alimentary tract. Am J Physiol Gastrointest Liver Physiol 293:G525-G531

Hentze MW, Muckenthaler MU, Galy B, Camaschella C (2010) Two to tango: regulation of Mammalian iron metabolism. Cell 142:24-38
Hertrampf E, Olivares M (2004) Iron amino acid chelates. Int J Vitam Nutr Res 74:435-443

Lash A, Saleem A (1995) Iron metabolism and its regulation. A review. Ann Clin Lab Sci 25:20-30

Lien EL, Boyle FG, Wrenn JM, Perry RW, Thompson CA, Borzelleca JF (2001) Comparison of AIN-76A and AIN-93G diets: a 13-week study in rats. Food Chem Toxicol 39:385-392

Nemeth E, Tuttle MS, Powelson J, Vaughn MB, Donovan A, Ward DM, Ganz T, Kaplan J (2004) Hepcidin regulates cellular iron efflux by binding to ferroportin and inducing its internalization. Science 306:2090-2093

Oliveira F, Rocha S, Fernandes R (2014) Iron metabolism: from health to disease. J Clin Lab Anal 28:210-218

Peto MV (2010) Aluminium and iron in humans: bioaccumulation, pathology, and removal. Rejuvenation Res 13:589-598

Ross SL, Tran L, Winters A, Lee KJ, Plewa C, Foltz I, King C, Miranda LP, Allen J, Beckman H, Cooke KS, Moody G, Sasu BJ, Nemeth E, Ganz T, Molineux G, Arvedson TL (2012) Molecular mechanism of hepcidin-mediated ferroportin internalization requires ferroportin lysines, not tyrosines or JAKSTAT. Cell Metab 15:905-917

Schneider BD, Leibold EA (2003) Effects of iron regulatory protein regulation on iron homeostasis during hypoxia. Blood 102:3404-3411

Singh AK, Ghosh TK, Haldar S (2015) Effects of methionine chelateor yeast proteinate-based supplement of copper, iron, manganese and zinc on broiler growth performance, their distribution in the tibia and excretion into the environment. Biol Trace Elem Res 164:253-260

Stoltzfus R (2001) Defining iron-deficiency anemia in public health terms: a time for reflection. J Nutr 131:565S-567S

Theil EC (2011) Iron homeostasis and nutritional iron deficiency. J Nutr 141:724S-728S

Vegarud GE, Langsrud T, Svenning C (2000) Mineral-binding milk proteins and peptides; occurrence, biochemical and technological characteristics. Br J Nutr 84(Suppl 1):S91-S98

Wan D, Zhou X, Xie C, Shu X, Wu X, Yin YL (2015) Toxicological evaluation of ferrous N-carbamylglycinate chelate: acute, subacute toxicity and mutagenicity. Regul Toxicol Pharmacol 73:644-651

Wang Y, Tang JW, Ma WQ, Feng J, Feng J (2010) Dietary zinc glycine chelate on growth performance, tissue mineral concentrations, and serum enzyme activity in weanling piglets. Biol Trace Elem Res 133:325-334

Weber TK, Freitas Kde C, Amancio OM, de Morais MB (2010) Effect of dietary fibre mixture on growth and intestinal iron absorption in rats recovering from iron-deficiency anaemia. Br J Nutr 104:1471-1476

Wilkinson N, Pantopoulos K (2014) The IRP/IRE system in vivo: insights from mouse models. Front Pharmacol 5:176

Wu X, Li J, Hu JN, Deng ZY (2012) The effects of glutamate and citrate on absorption and distribution of aluminum in rats. Biol Trace Elem Res 148:83-90

Wu X, Yin Y, Shu X (2013) Dipeptide chelated iron and a preparation method for feed additives. Patents, China

Wu X, Wan D, Xie C, Li T, Huang R, Shu X, Ruan Z, Deng Z, Yin Y (2015) Acute and sub-acute oral toxicological evaluations and mutagenicity of N-carbamylglutamate (NCG). Regul Toxicol Pharmacol 73:296-302

Zhou X, Wu X, Yin Y, Zhang C, He L (2012) Preventive oral supplementation with glutamine and arginine has beneficial effects on the intestinal mucosa and inflammatory cytokines in endotoxemic rats. Amino Acids 43:813-821 